\title{
Ekspektasi Komunitas Kamera Nikon: Brand Personality dalam Mempertahankan Brand Loyalty
}

\author{
N. Renata, B. Widjajanta \& P.D Dirgantari \\ Universitas Pendidikan Indonesia \\ natasharenata@student.upi.edu
}

\begin{abstract}
The purpose of the research is to find out the influence of brand personality on brand loyalty. The object becomes the unit of analysis in this research is camera Nikon community Indonesia. The type of research is using descriptive with the explanatory method survey of 106 respondents. The results of this research indicate that the brand personality in the good category and brand loyalty in the good category. In this research findings if the conditions of the brand personality is good, then it will increase brand loyalty.
\end{abstract}

\section{Keywords: Brand Personality; Brand Loyalty}

Abstrak: Tujuan penelitian yaitu untuk mengetahui pengaruh brand personality terhadap brand loyalty. Objek yang menjadi unit analisis dalam penelitian ini adalah komunitas kamera Nikon di Indonesia. Jenis penelitian yang digunakan adalah deskriptif dengan metode yang digunakan explanatory survey dengan jumlah sampel 106 responden Hasil penelitian ini menemukan bahwa brand personality berkategori baik dan brand loyalty berkategori baik. Dalam penelitian ini ditemukan jika brand personality baik, maka akan meningkatkan brand loyalty.

Kata Kunci: Brand Personality; Brand Loyalty

\section{PENDAHULUAN}

Perusahaan-perusahaan berkembang sangat pesat di era globalisasi seperti sekarang ini, masyarakat dapat memenuhi kebutuhannya dengan sangat mudah bahkan memiliki lebih banyak alternatif dalam penentuan produk untuk memenuhi kebutuhannya (Rasheed, 2015). Perkembangan ini membuat persaingan semakin ketat sehingga menyebabkan perusahaan sulit untuk meningkatkan jumlah pelanggan karena terlalu banyak produk dengan keunggulan dan nilai lebih yang ditawarkan oleh para pesaing (Lawrence \& Benjamin, 2014). Membangun merek yang kuat dan sehat, sangat penting untuk dilakukan guna menciptakan keunggulan kompetitif perusahaan yang berkelanjutan (Lam, Ahearne, Hu, \& Schillewaert, 2010), loyalitas merek (Brand loyalty) masih menjadi perhatian penting perusahaan terutama dengan munculnya platform media sosial yang membuat merek lebih mudah untuk berinteraksi dan terlibat dengan konsumen (Wilimzig, 2011). Loyalitas merek (Brand loyalty) mencerminkan tingkat keterikatan konsumen dengan satu merek produk (Yudianto, Psikologi, \& Utara, 2010).

Perubahan perilaku dan selera konsumen membuat gaya hidup baru bagi konsumen (Studi et al., 2014). Semakin beragamnya selera konsumen semakin tingginya pertumbuhan industri-industri yang mendukung gaya hidup tersebut, salah satunya adalah industri teknologi digital (haryoracmantyo, 2000). Teknologi Digital merupakan teknologi yang dilihat dari pengoperasionalannya tidak lagi banyak menggunakan tenaga manusia. Tetapi lebih cenderung pada sistem pengoperasian yang serba otomatis dan canggih dengan sistem komputerisasi/format yang dapat dibaca oleh komputer. (Mahmud \& Gope, 2012). Beberapa peralatan yang menggunakan teknologi digital antara lain komputer, laptop, telegraf, radio, televisi, kamera, CCTV, modem, sateletit 
komunikasi, harddisk, flashdisk dan peralatan teknologi digital lainnya (Hasan, n.d, 2014). Brand loyalty dapat tercipta karena pelanggan merasa puas dengan produk, bisa berupa barang atau jasa yang dibelinya (Kabadayi \& Price, 2014). Pelanggan yang loyal lebih berharga dalam waktu dekat dan dalam jangka waktu panjang, mereka memikirkan bisnis masa depan.

\section{METODE PENELITIAN}

Metode penelitian yang digunakan adalah metode explanatory survey. Explanatory survey dilakukan untuk mengeksplorasi situasi masalah, yaitu untuk mendapatkan ide-ide dan wawasan kedalam masalah yang dihadapi manajemen atau para peneliti tersebut (Maholtra, 2010:96). Penelitian deskriptif adalah jenis penelitian konklusif yang memiliki tujuan utama deskriptif dari sesuatu,biasanya karakteristik atau fungsi pasar (Hasan, n.d, 2014).

Penelitian yang berupa deskriptif ini mempunyai maksud untuk mengetahui gambaran mengenai pengaruh brand personality terhadap brand loyalty di komunitas kamera Nikon. Penelitian ini dilakukan pada kurun waktu kurang dari satu tahun,maka metode yang digunakan metode dengan cara mempelajari objek dalm kurun waktu tertentu tidak berkesinambungan dalam jangka panjang (Nawaz \& Usman, 2008). Pengumpulan informasi dari subjek penelitian hanya dilakukan satu kali dalam satu periode waktu, sehingga penelitian ini merupakan one-shot (Kocak Alan \& Kabadayi, 2012). Jenis data yang HASIL DAN PEMBAHASAN

Aaker dan Sirgy dalam (Malär, Krohmer, Hoyer, \& Nyffenegger, 2011) mengatakan kepribadian merek dapat berperan dalam membantu konsumen mengekspresikan konsep diri mereka dan memberikan rasa nyaman kepada konsumen yang telah menemukan merek yang "sesuai" konsep diri mereka. Secara keseluruhan brand personality $(\mathrm{X})$ yang terdiri dari Sincerity digunakan dalam penelitian ini adalah data primer dan data sekunder. Penggunaan data primer bertujuan untuk memperoleh gambaran nyata dari pihak yang mengetahui ataupun memiliki data tentang penelitian ini. Sedangkan, data sekunder merupakan data primer atau oleh pihak lain. Teknik pengumpulan data mengacu pada cara apa yang perlu dilakukan dalam penelitian agar dapat memperoleh data. Teknik pengumpulan data dapat dilakukan dengan cara kombinasi secara langsung atau tidak langsung.

Pengujian validitas instrumen dilakukan untuk menjamin bahwa terdapat kesamaan antara data yang terkumpul dengan data yang sesungguhnya terjadi pada objek yang diteliti, pengujian reliabilitas menunjukkan bahwa setiap instrument cukup dapat dipercaya untuk digunakan sebagai alat pengumpul data, karena instrumen tersebut sudah baik dan dapat menghasilkan data yang dapat dipercaya. populasi dalam penelitian ini adalah Komunitas Kamera Nikon Indonesia di Kota Bandung sebanyak 40.830 anggota pada bulan Agutus tahun 2018. Sampel yang digunakan dalam penelitian ini adalah sebagian dari populasi, yaitu sebagian jumlah pengguna kamera Nikon di Indonesia. Rumus yang digunakan untuk mengambil suatu sampel dari sebuah populasi ialah dengan menggunakan rumus Tabachnick dan Fidell (Tabachnick \& Fidell, 2013), dalam penelitian ini ukuran sampel minimal dalam penelitian ini adalah 106 responden.

(Ketulusan), Excitement (Ketertarikan), Competence (Kemampuan), Sophistication (Keduniawian), dan emotionality (emosionalitas) dapat diketahui kedudukannya berdasarkan skor yang didapat dari rekapitulasi data. Rekapitulasi dimensi dari variabel brand personality (X) tersebut dapat dilihat pada Tabel 4.10 berikut ini: 
TABEL 1.

REKAPITULASI TANGGAPAN MENGENAI DIMENSI BRAND PERSONALITY

\begin{tabular}{clccc}
\hline \multirow{2}{*}{ No } & \multicolumn{1}{c}{ Dimensi } & $\begin{array}{c}\text { Perolehan } \\
\text { Skor }\end{array}$ & Skor Ideal & $(\boldsymbol{\%})$ \\
\hline 1 & Sincerity (Ketulusan) & 2.331 & 2.968 & 78,53 \\
2 & Excitement (Ketertarikan) & 2.305 & 2.968 & 77,66 \\
3 & Competence (Kemampuan) & 1.790 & 2.226 & 80,41 \\
4 & Sophistication (Keduniawian) & 1.134 & 1.484 & 76,41 \\
5 & Ruggedness (Kekuatan) & 1.222 & 1.484 & 82,34 \\
\hline Total & & 8.782 & 11.130 & 78,72 \\
\hline
\end{tabular}

Sumber: Hasil Pengolahan Data, 2019

Berdasarkan Tabel 1 hasil pengolahan data yang telah dilakukan melalui penyebaran instrumen kepada 106 kamera Nikon di Komunitas kamera Nikon Indonesia, apabila di persentasekan skor tertinggi terdapat pada dimensi Ruggedness (Kekuatan) sebesar 82,34\% hal tersebut ketahanan sebuah produk diperlukan untuk menguatkan merek (Louis \& Lombart, 2010). Artinya terdapat ketahan produk seperti yang diinginkan konsumen dalam menunjang berbagai keadaan yang konsumen inginkan karena betapa pentingnya strategi untuk selalu mengerti apa yang dibutuhkan konsumen dan ketahanan produk yang dimiliki merek tersebut.

Skor terendah diperoleh pada dimensi Sophistication (Keduniawian) sebesar 76,41\% hal tersebut disebabkan pengguna kamera Nikon merasa gengsi bukan merupakan hal penting dalam pemilihan kamera.

Berdasarkan hasil pengolahan data yang telah dilakukan melalui penyebaran kuesioner pada Komunitas kamera Nikon dapat diukur melalui perhitungan skor dimensi dari brand personality. Skor brand personality sebesar 8762 sedangkan skor ideal loyalitas merek itu sendiri adalah 11130. Perbandingan ini menunjukan bahwa pada pelaksanaan brand personality perusahaan Nikon telah berlangsung dengan baik.

Diterapkan dalam perusahaan kamera Nikon didefinisikan brand loyalty dapat menjadi panduan dan kriteria dalam kerangka aktivitas untuk membangun merek yang lebih kuat. Loyalitas merupakan investasi terbesar dan berjangka panjang yang sangat menguntungkan perusahaan karena dapat membantu perusahaan meningkatkan profitabilitas, menekan biaya pemasaran dan memperluas pangsa pasar. Konsumen yang loyal akan memberikan keuntungan dengan kecenderungannya melakukan pembelian ulang dan merekomendasikannya pada lingkungan sekitar. Hal ini yang menyebabkan pembentukan loyalitas konsumen menjadi orientasi utama setiap perusahaan (Devindiani \& Wibowo, 2016). Secara keseluruhan brand loyalty (Y) yang terdiri dari Behavior, Switching cost, Measuring satisfaction, Measuring liking the brand, Commitment dapat diketahui kedudukannya berdasarkan skor yang didapat dari rekapitulasi data. Rekapitulasi dimensi dari variabel brand loyalty (Y) tersebut dapat dilihat pada Tabel 2 berikut ini:

TABEL 2.

\section{REKAPITULASI TANGGAPAN MENGENAI DIMENSI} BRAND LOYALTY

\begin{tabular}{|c|c|c|c|c|}
\hline No & Dimensi & $\begin{array}{l}\text { Perolehan } \\
\text { Skor }\end{array}$ & Skor Ideal & $(\%)$ \\
\hline 1 & Behavior (pengukuran perilaku) & 1.170 & 1.484 & 78,84 \\
\hline 2 & Switching cost (biaya peralihan) & 1.129 & 1.484 & 76,07 \\
\hline 3 & Measuring satisfaction (pengukuran kepuasan) & 606 & 742 & 81,67 \\
\hline 4 & $\begin{array}{l}\text { Measuring liking the brand (pengukuran } \\
\text { kesukaan terhadap merek) }\end{array}$ & 1.168 & 1.484 & 78,70 \\
\hline 5 & Commitment (komitmen) & 1.209 & 1.484 & 81,46 \\
\hline Total & & 5.282 & 6.678 & 79,14 \\
\hline
\end{tabular}

Sumber: Hasil Pengolahan Data, 2019 
pengguna kamera Nikon di Komunitas kamera Nikon Indonesia, apabila di persentasekan skor tertinggi terdapat pada dimensi Measuring satisfaction (pengukuran kepuasan) sebesar $81,67 \%$ hal tersebut semakin tinggi rasa puas konsumen dalam menggunakan kamera merek Nikon semakin tinggi pula rasa suka terhadap merek Nikon tersebut maka terciptalah loyalitas terhadap suatu merek. Skor terendah diperoleh pada dimensi Switching cost (biaya peralihan) sebesar 76,07\% hal tersebut disebabkan konsumen merasa biaya tambahan suatu produk dapat mengurangi kepuasan terhadap produk tersebut atas biaya awal yang telah dikeluarkan saat pembelian pertama..

Hasil tabel 4.16 menunjukkan bahwa secara keseluruhan memperoleh skor 5282 dengan presentase $79,14 \%$ yang artinya responden loyal pada kamera merek Nikon. dimensi yang memiliki penilaian paling tinggi adalah kepuasan yang merupakan indikator dari loyalitas dan merupakan faktor pembentuk loyalitas merek (Thiela \& Mackay, 2013).

Berdasarkan hasil pengolahan data yang telah dilakukan melalui penyebaran kuesioner pada anggota komunitas kamera Nikon di Indonesia, dapat diukur melalui perhitungan skor dimensi dari Brand Loyalty. Skor total Brand Loyalty sebesar 5282 sedangkan skor idealnya adalah 6.678. Perbandingan ini menunjukan bahwa pada pelaksanaan Brand Loyalty pada pelanggan kamera Nikon di Indonesia telah berlangsung dengan cukup baik, Dengan hasil perolehan nilai ini dapat disimpulkan bahwa dalam perusahaan kamera Nikon di Indonesia, penciptaan Brand Loyalty sudah menunjukkan kinerja yang diharapkan walaupun belum optimal, mengingat begitu pentingnya Brand Loyalty dalam menunjang perilaku positif dari konsumen

\section{KESIMPULAN DAN SARAN}

Berdasarkan hasil penelitian dari kuesioner yang disebar kepada 106 responden, dapat diketahui bahwa brand personality produk kamera Nikon pada Komunitas kamera Nikon mendapatkan skor sebesar 8782 atau persentasenya sebesar $78,72 \%$ dari skor ideal yaitu 11.130. Jika dilihat berdasarkan dimensi, dimensi yang mendapat skor paling tinggi adalah dimensi ruggedness dengan perolehan skor sebesar 1222 atau dengan persentase $82,34 \%$. Sementara dimensi yang mendapatkan skor paling rendah adalah dimensi Sophistication dengan perolehan skor sebesar 1.134 atau dengan persentase $76,41 \%$. Jika dilihat berdasarkan indikator, indikator yang mendapatkan skor paling tinggi adalah daya tahan atau kekuatan kamera merek Nikon skor 618. Sedangkan indikator yang mendapatkan skor paling rendah adalah kesederhanaan yang di cerminkan kamera merek Nikon perolehan skor 554.

Dapat diketahui bahwa brand loyalty produk kamera Nikon pada Komunitas kamera Nikon mendapatkan skor sebesar 5282 atau persentasenya sebesar $79,14 \%$ dari skor ideal yaitu 6678. Jika dilihat berdasarkan dimensi, dimensi yang mendapat skor paling tinggi adalah dimensi measuring satifaction dengan persentase $81,67 \%$. Sementara dimensi yang mendapatkan skor paling rendah adalah dimensi switching cost dengan perolehan persantase $76,07 \%$. Jika dilihat berdasarkan indikator, indikator yang mendapatkan skor paling tinggi adalah Setiap produk Nikon berdasarkan persepsi pelanggan loyalitas merek itu ditunjukkan melalui kepuasan pada suatu merek sebagai pilihan utama. (Podoshen \& Podoshen, 2012) mendefinisikan loyalitas merek sebagai komitmen yang mendalam untuk melakukan pembelian ulang atau berlangganan pada suatu barang/jasa yang menjadi preferensinya secara konsisten di masa yang akan datang dengan perolehan skor 606. Sedangkan indikator yang mendapatkan skor paling rendah adalah biaya peralihan tampak memiliki pengaruhnya pada loyalitas merek karean pada umumnya jika biaya untuk berganti merek sangat mahal maka pelanggan enggan untuk berganti merek dengan perolehan skor 564 .

Gambaran mengenai brand personality dapat dilihat dari dimensi-dimensinya yang terdiri dari Sincerity, excitement, competence, sophistication dan ruggedness berada pada kategori baik. Hal ini menunjukan bahwa brand personality yang diberikan Nikon dapat dikatakan baik. Dimensi Ruggedness memiliki persentase penilaian paling tinggi, sedangkan dimensi sophistication memiliki persentase penilaian paling rendah.

Adapun rekomendasi untuk beberapa indikator brand personality yang dianggap memiliki nilai terendah adalah sebagai berikut:

a. Perusahaan disarankan untuk lebih menyederhanakan kembali produk kamera 
Nikon dalam mengoperasikan kameranya, maupun desain. Hal tersebut semakin mempermudah konsumen dalam menggunakan kamera Nikon.

b. Perusahaan disarankan untuk mempercepat dalam melakukan pengembangan produk dengan cara memberikan kualitas yang up to date sesuai dengan apa yang dibutuhkan konsumen sehingga konsumen lebih tertari dalam membeli produknya kamera Nikon yang mengikuti perkembangan zaman.

c. Perusahaan disarankan untuk lebih mengembangkan tekhnologi yang ada pada kamera Nikon sehingga kamera Nikon dapat menjadi Kamera yang cerdas dan memenuhuhi semua kebutuhan konsumen dalam mengambil foto maupun video.

d. Perusahaan disarankan memberikan nilai lebih dan kesan mewah pada kamera Nikon, hal tersebut dapat membuat konsumen merasakan eksklusifitas yang dibentuk oleh prestise, citra merek, maupun tingkat daya tarik pada pelanggan.

e. Perusahaan disarankan untuk meningkatkan kamera Nikon yang mendukung aktifitas diluar rumah, sehingga dapat membuat konsumen dapat menggunakan kamera Nikon dalam keadaan apapun dan dimanapun.

Dan Adapun rekomendasi untuk beberapa indikator brand loyalty yang dianggap memiliki nilai terendah adalah sebagai berikut:

a. Perusahaan harus menigkatkan rasa suka dan tertarik terhadap merek tersebut dengan cara mengkomunikasikan produk yang dijual dengan baik, memberikan pelayanan yang baik dan memberikan produk kamera Nikon yang lebih berkualitas sehingga pelanggan melakukan pembelian ulang terhadap poduk kamera Nikon.

b. Perusahaan harus meminimalisir biaya tambahan terhadapa pembelian produk kamera Nikon sehingga pengguna kamera Nikon tidak perlu memberikan biaya tambahan pada saat pembelian kamera Nikon

\section{DAFTAR PUSTAKA}

Devindiani, E., \& Wibowo, L. A. (2016). Pengaruh Experiential Marketing Terhadap Customer Satisfaction Serta Dampaknya Pada
Customer Loyalty ( Survei pada Pengguna Smartphone di Komunitas Online Apple dan Samsung Regional Bandung ). Pendidikan Manajemen Bisnis, 1(1), 147-157.

haryoracmantyo. (2000). No Title. Brand Community, 1-45.

Hasan. (n.d.). 3205_Yi_loyaltyprogram1.pdf (p. 2014). p. 2014.

Kabadayi, S., \& Price, K. (2014). Consumer Brand engagement on Facebook: liking and commenting behaviors. Journal of Research in Interactive Marketing, 8(3), 203-223. https://doi.org/10.1108/JRIM-12-2013-0081

Lam, S. K., Ahearne, M., Hu, Y., \& Schillewaert, N. (2010). Resistance to Brand Switching When a Radically New Brand Is Introduced: A Social Identity Theory Perspective. Journal of Marketing, 74(6), 128-146. https://doi.org/10.1509/jmkg.74.6.128

Lawrence, R. B., \& Benjamin. (2014). Engaging Communities for the Company and the Brand. $1-27$.

Louis, D., \& Lombart, C. (2010). Impact of brand personality on three major relational consequences (trust, attachment, and commitment to the brand). Journal of Product \& Brand Management. https://doi.org/10.1108/10610421011033467

Love, E., Staton, M., \& Rotman, J. D. (2016). Loyalty as a matter of principle: the influence of standards of judgment on customer loyalty. Marketing Letters, 27(4), 661-674. https://doi.org/10.1007/s11002-015-9371-0

Mahmud, K., \& Gope, K. (2012). Factors Influencing The Extent of Brand Loyalty. 12(15).

Maholtra, K. N. (2010). Marketing Reseach: An Applied Orientation Sixth Ed Pearson Education (Sixth edit). Pearson Education.

Malär, L., Krohmer, H., Hoyer, W. D., \& Nyffenegger, B. (2011). Emotional Brand Attachment and Brand Personality: The Relative Importance of the Actual and the Ideal Self. Journal of Marketing, 75, 35-52. 
Rasheed, K. O. (2015). Product Package as Determinant of Brand Loyalty in Food and Beverages Markets of Lagos State ,. American Journal of Marketing Research, 1(3), 150-157.

Rostami, A. R., Valmohammadi, C., \& Yousefpoor, J. (2014). The relationship between customer satisfaction and customer relationship management system; a case study of ghavamin bank. Industrial and Commercial Training, 46(4), 220-227. https://doi.org/10.1108/ICT-10-2013-0067

Studi, P., Komunikasi, I., Ilmu, F., Dan, S., Politik, I., Atma, U., \& Yogyakarta, J. (2014). Pengaruh elemen komunitas merek terhadap loyalitas merek.

Sugiyono. (2014). Metode Penelitian Kuantitatif Kualitatif dan $R \& D$. Bandung: Alfabeta.

Thiela, S. R., \& Mackay, M. M. (2013). Assessing the performance of brand loyalty measures. Journal of Service Marketing, 15(7), 529546.

Wilimzig, B. J. (2011). Online Communities: Influence on Members Brand Loyalty and Purchase Intent.

Yudianto, Y., Psikologi, F., \& Utara, U. S. (2010). Pengaruh Brand Community Terhadap Loyalitas Merek Sepeda motor Yamaha. 179. 